\title{
CULTURAS NA ESCOLA E O CURRÍCULO BREVE: EPISÓDIOS DE APRENDIZAGEM SITUADA NA FORMAÇÃO
}

\author{
Pier Cesare RIVOLTELLA ${ }^{\mathrm{i}}$
}

Monica FANTIN ${ }^{\text {ii }}$

\begin{abstract}
RESUMO
O artigo situa alguns desafios da complexidade e da cultura digital na escola e no currículo a partir de aspectos históricos e culturais. As metáforas do currículo sinalizam visões de mundo e de educação, ao mesmo tempo em que falam e traduzem aspectos da imaginação diante de certos desafios da escola. Nessa perspectiva, o artigo situa a possibilidade de práticas disruptivas a partir da ideia do "currículo breve" presente na metodologia dos Episódios de Aprendizagem Situada, EAS, destacando algumas narrativas de estudantes em um contexto formativo universitário. Por fim, conclui que a metodologia EAS pode ser considerada uma abordagem diferente de currículo ao desarticular o discurso pedagógico tradicional, com sua moldura rígida que viabiliza o dispositivo da escola, para ser reconceitualizado como um texto que se faz, desfaz e refaz na prática pedagógica, nas mediações e interações, construídas entre professores e alunos, e nos diálogos com as culturas na escola e fora dela.
\end{abstract}

PALAVRAS-CHAVE: Cultura digital; Currículo; Episódios de Aprendizagem Situada.

\section{SCHOOL CULTURES AND SHORT CURRICULUM: TEACHING WITH EPISODES OF SITUATED LEARNING}

\begin{abstract}
The article reflects on challenges created by complexity and digital culture in schools and curriculums from an historical and cultural perspective. Metaphors used for a curriculum indicate perspectives on the world and education and simultaneously express aspects of the imagination in relation to school challenges. In this context, the article presents opportunities for disruptive practices based on the idea of the "short curriculum" present in the Situated Learning Episodes methodology, highlighting narratives of higher education students. The article concludes that the Episodes of Situated Learning methodology can be considered an optional approach to curriculum; because it deconstructs the rigid framework of traditional school pedagogy. It reconceptualizes curriculum as a text to be built and rebuilt through pedagogical practice, in mediations and interactions among teachers and students, and in dialogues with cultures in and outside schools.
\end{abstract}

KEYWORDS: Digital Culture, Curriculum, Situated Learning Episodes.

\footnotetext{
${ }^{\text {i }}$ Doutor em Filosofia pela Universita Cattolica del Sacro Cuore di Milano (1988). Atualmente é professor adjunto da Universita Cattolica del Sacro Cuore di Milano. E-mail: piercesare.rivoltella@gmail.com.

ii Doutora em Educação pela Universidade Federal de Santa Catarina com Estágio no Exterior, na UCSC, Milão, Itália. Realizou Pós-Doutorado em Estética no Departamento de Filosofia da Università Cattolica del Sacro Cuore, Milano. Professora Associada do Centro de Educação da Universidade Federal de Santa Catarina. E-mail: fantin.monica@gmail.com.
} 


\section{CULTURAS EN LA ESCUELA: \\ EPISODIOS DE APRENDIZAJE SITUADO EN LA FORMACION}

\section{RESUMEN}

El artículo coloca algunos desafíos de complejidad y cultura digital en la escuela y en el plan de estudios desde algunos aspectos históricos y culturales. Las metáforas del currículo señalan algunas visiones del mundo y de la educación, al mismo tiempo que hablan y traducen aspectos de la imaginación frente a ciertos desafíos escolares. En esta perspectiva, el artículo sitúa la posibilidad de prácticas disruptivas basadas en la idea del "currículum breve" presente en la metodología de los Episodios de Aprendizaje Situado, EAS, destacando algunas narrativas de estudiantes producidas en un contexto de educación universitaria. Se concluye que la metodología EAS puede considerarse un enfoque diferente sobre el curricolo porque permite desmantelar el discurso pedagógico tradicional con su marco rígido, hacendo que el dispositivo escolar sea factible. En este sentido, el curricolo è reconceptualizado como un texto que se hace, deshace y rehace en la práctica pedagógica, en mediaciones y interacciones construidas entre profesores y alumnos, y en diálogos con culturas en la escuela y fuera.

PALABRAS CLAVE: Cultura digital; Curriculum; Episodios de Aprendizaje Situado.

\section{INTRODUÇÃO}

As formas de produzir e compartilhar o conhecimento no contexto da cultura digital estão passando por profundas transformações provocadas por meios e tecnologias, que também transformam nossas percepções, saberes, valores, culturas e formas de ensinar-aprender. Refletir sobre a presença da cultura contemporânea na escola e reorganização dos conhecimentos, por vezes instantâneos e descontínuos neste espaço social, nos leva a pensar na inserção curricular das mídias/tecnologias, nos dispositivos móveis e seus aplicativos, além de tantos outros artefatos que promovem mudanças nas formas-conteúdos, nas relações pedagógicas e nos modos de ensinar e aprender em todos os níveis de escolaridade.

Mais que instrumentos e ambientes, atualmente, as mídias configuram o próprio tecido conectivo em que tecemos nossas relações e interações, como destaca Rivoltella (2017), quando se refere à mediamorfose (FIDLER, 1997) relacionada à conceitualização das mídias, seus temas chaves e suas ideias da tecnologia. Assim, entendemos as mídias digitais, não apenas (ou não mais?) como ferramentas ou ambientes dos processos científicos, culturais e educacionais, mas como espaço social fundamental, ou seja, como dimensões que pertencem à vida das pessoas, conforme destaca Floridi (2014) quando fala provocativamente que a mídia, hoje, é onlife.

Ao refletir sobre o entorno tecnológico, as necessidades didáticas e culturais da escola e suas interfaces, entendemos o currículo: como artefato social e cultural, o que significa 
contextualizar determinações históricas e sociais, bem como implicações nas relações de poder (SILVA, 1996); como prática cultural, que significa entender o currículo também como produção de sentidos e significados (FANTIN, 2012); como objeto de design, no sentido do trabalho teórico de Diana Laurillard (2012) e da perspectiva de uma filosofia didática que se fundamenta na complementariedade entre macro e micro learning (RIVOLTELLA \& ROSSI, 2019). Um currículo entendido em sua multiplicidade e singularidade/particularidade pode atuar como fio condutor das tramas tecidas no contexto desse ecossistema comunicativo, pedagógico e cultural que é a escola. E entender a perspectiva de um currículo como tempo breve e como possibilidade de repensar os conteúdos na lógica de sua redução, presente na metodologia dos Episódios de Aprendizagem Situada, EAS, (RIVOLTELLA, 2013) pode ser um ponto de partida e abertura ao diálogo com o novo, como um dispositivo de produção de conhecimentos, relações, identidades e outras formas de pertencimento na escola e na cultura.

\section{CURRÍCULO E CULTURA DIGITAL: CONTEXTOS, METÁFORAS E DESAFIOS}

As teorias clássicas do currículo podem ser entendidas a partir de algumas fases que revelam tensões e contradições entre diferentes centralidades e protagonismos que colocam em questão/jogo e se modificam conforme o momento histórico: centralidades no aluno/na aprendizagem, na didática/ensino e na escola/percurso formativo. E cada escolha sempre produz seus questionamentos, destaca Rivoltella (2018), que atualmente observa um retorno de centralidade no currículo a partir da lógica de competências e da necessidade de certificá-las, da verticalização do ensino e outros aspectos que recolocam o currículo no centro da escola e no percurso de formação. Para o autor, a organização temporal do percurso em determinada direção, hoje responderia a substancialmente duas necessidades: 1) didática, relacionada à ideia de "declinação"/desdobramento, no sentido de "dar corpo" às competências e indicações dos Ministérios de Educação; 2) cultural, caracterizada pelo crescimento rápido e exponencial do saber. Desse modo, emerge a necessidade de se orientar nesses saberes, pois para Rivoltella (2018), o currículo na escola desenvolve uma função cultural para favorecer "a ordem no caos" entre os alunos, como veremos mais adiante.

Esse caos também pode ser entendido diante da ambiguidade de uma realidade social que, num curto espaço de tempo, foi da efervescência de ocupações nas escolas aos tempos sombrios de perdas de direitos em diversos sentidos, conforme estamos vivendo atualmente no contexto brasileiro. [Sem entrar no mérito do contexto atual da pandemia e as implicações 
políticas, econômicas, sociais e culturais que já estamos vivendo.] Um cenário de sombras, de muitas perguntas e poucas respostas.

Uma breve retrospectiva sobre os movimentos curriculares em diferentes contextos socioculturais nos leva a tensionar a ideia da base comum, das diretrizes da educação nacional, dos movimentos contrários à implantação e suas resistências, dos Planos Nacionais de Educação e seus sistemas [unificados] de ensino, das reformas e contrarreformas, do caráter autoritário de certas "medidas provisórias", das propagandas enganosas e, sobretudo, a desconsideração do acúmulo de debates que mascaram certos itinerários formativos e muitas outras questões que revelam uma tendência à degradação e precarização do ensino cada vez maior. Tais questões somam-se ao silêncio diante de tantos outros aspectos que não querem calar. Assim, por mais incômoda que possa ser a indagação de Sibilia "enquanto deslizamos velozmente a bordo desse século XXI que tantas surpresas nos tem trazido, ostentando seus feitiços tecnológicos e seu estilo de vida globalizado, será que a escola se tornou obsoleta?" (2012, p.9), precisamos assumir que o dispositivo escola precisa ser radicalmente transformado ou mesmo reinventado, ou, quem sabe, deconstruído para além das "redes ou paredes".

Afinal, quem trabalha com educação trabalha também com esperança, como dizia Paulo Freire (2016), portanto há que ter o cuidado para não cair no fatalismo e nem abrir mão da esperança, pois "sempre é possível criar algo para além da simples resistência às propostas oficiais", lembra Alves (2017, p.5). É o que Franco Basaglia (1979), nos anos 1970, considerava nas suas conferências brasileiras sobre a desinstitucionalização da psiquiatria; vale para a escola o que ele pensava sobre os hospitais psiquiátricos. Ou seja, que o verdadeiro problema é sempre problema de poder, e imaginar uma nova psiquiatria (no nosso caso: una nova escola) quer dizer pensar além das relações de poder. Se o currículo não é apenas veículo de algo a ser transmitido, mas arena política e terreno em que se cria e produz cultura, "os materiais existentes funcionam como matéria-prima de criação, recriação e, sobretudo, de contestação e transgressão", dizem Moreira e Silva (1995, p. 28).

Nessa perspectiva, a necessidade de crítica à ideia de uma organização curricular entendida como acúmulo de disciplinas, que pouco dizem sobre a vida, deve estar articulada à precariedade da infraestrutura escolar e da formação, bem como a uma estética escolar e arquitetura de gosto duvidoso que também contribui para explicar a produção do fracasso escolar. Tal crítica também deve rever os modelos curriculares e suas metáforas para pensar outras/novas respostas/possibilidades diante das velhas perguntas: Como se constrói uma 
autoridade cultural para o currículo quando se considera difícil enunciar alguma lei ou saber válido para todos? Quais os principais desafios do currículo no contemporâneo?

A esse respeito, Dussel (2014) faz uma reflexão que compreende o currículo moderno como um "documento público que expressa uma síntese de uma proposta cultural, formulada em termos educativos, sobre como e quem define a autoridade cultural em determinada sociedade" (2014, p.1). A autora traz para o debate curricular algumas mudanças e polêmicas suscitadas pela tecnocultura e cultura digital, questionando a centralidade do texto curricular e propondo outros critérios de organização e hierarquização dos saberes, bem como outras operações baseadas no "gosto dos consumidores" e em suas respostas emocionais. A seguir, trazemos ideias de Dussel (2013 e 2014) para esta discussão.

$\mathrm{Na}$ história do currículo, e suas margens que emergem na modernidade expressando certa vontade de ordenar e unificar o ensino supondo uma organização em duas dimensões, a disciplina (sentido de coerência estrutural) e a ordem (sentido de sequência interna), com a promessa de abarcar os conhecimentos em uma lógica sequencial gerou demandas de "seguir o currículo" e complementá-lo, o que impôs certo controle sobre as práticas de ensino, cada vez mais centralizadas, e homogeneizadas, com pouca abertura a negociações. Ainda que a existência de um objeto concreto que pudesse transportar, ler em diferentes cenários e atuar como referência e memória para ordenar práticas tenha sido vital, essa forma de pensar o currículo está em crise, uma crise que não é apenas teórica, destaca Dussel (2013).

A crise dos estudos curriculares não diz respeito apenas ao esgotamento de certas tradições intelectuais internas ao campo, pois os questionamentos tomam novas formas e se ampliam com as mudanças tecnoculturais e políticas, questionando a centralidade e hierarquização dos saberes do currículo moderno. Assim, a contestação e a crítica vão além das questões internas do currículo e remetem a um movimento mais amplo da reação saber-poder que a autora aborda a partir de algumas metáforas.

Entre modelos e metáforas para pensar o currículo e seus entornos tecnológicos, Dussel (2013) menciona o currículo como o atlas, coleção, ou árvore do conhecimento; o currículo como mapa; o currículo como monumento; e como biblioteca e arquivo, que por sua vez são também ícones do conhecimento na modernidade. Na organização do conhecimento baseado na acumulação, tradição e autoridade, a visão de território que se vê de fora é a base de noções que hoje identificamos nos parâmetros curriculares, níveis de aprendizagem, conteúdos básicos e outros que envolvem um corpo de saberes mínimos e comuns para todos. E para a autora, tais 
imagens de um saber centralizado tensionam com imagens de projetos curriculares contemporâneos a partir das artes e da literatura no desenho da teoria social que a autora busca rearticular e, com um olhar pós-crítico à reflexão e ação curricular, reconduz certos problemas para pensar o currículo contemporâneo.

As mudanças que temos vivido mais recentemente remetem a novas organizações da cultura e da política entendidas como heranças que vão se substituindo desde os anos 1960, e suas mudanças tecnoculturais propiciaram outras formas de transmissão e hierarquia de saberes. A internet, os novos meios digitais e seus dispositivos móveis instalam novas práticas de cidadania multiletrada, e a ideia de uma cultura comum que estruturava o currículo escolar está modificando a hierarquia de saberes, proposta pela cultura escolar. Assim, os novos meios da cultura digital foram "desorganizando" esse cenário, e a cultura pública foi migrando para as redes, embora ainda persistam as exclusões digitais e os abismos sociais e territoriais, como diz Ito e seus colegas (2010). Para autores como Jenkins (2009) e Pretto (2017), a passagem da ideia de audiências de cinema e televisão para "públicos em rede" propicia a "participação ativa" em uma rede social distribuída na produção e circulação da cultura e do conhecimento que modifica definitivamente as relações entre si e com o saber. E nem sempre tais aspectos são considerados no currículo.

Nesse sentido, podemos indagar quais as nuances da relação entre mídia, escola e currículo com a presença generalizada da mídia no mundo contemporâneo que por vezes nos leva a verdadeiros impasses diante das transformações de inúmeros conceitos-chave para compreender o momento atual trazido para a educação, escola, currículo e formação do professor. Aliado a isso, Pretto $(2004,2017)$ nos lembra que a intensificação da cultura digital e da concentração das grandes empresas/corporações de comunicação trouxe também movimentos contra-hegemônicos que articulam possibilidades de destacar os valores locais a partir da ideia de múltiplas culturas e das redes. Para o autor, a perspectiva online expõe ao limite a ideia do mundo sendo transmitido para o mundo, montando e desmontando, construindo e desconstruindo discursos, práticas e percepções éticas e estéticas.

Nesse contexto, por mais óbvio que seja/pareça, é importante lembrar que a alta velocidade e aceleração que promove os mais diversos tipos de mobilidades e deslocamentos físico, de informações, de imagens - alteram de forma substancial nossa percepção espaciotemporal, além da condição de vivermos praticamente conectados em tempo real e com absolutamente quase tudo. E esse modelo que veio da comunicação, baseado em uma lógica de 
broadcasting ou de produção centralizada e distribuição em massa, incentivou a produção simbólica gerando subprodutos em outras áreas do conhecimento, sobretudo na cultura e na educação, contribuindo também para uma visão produtivista da educação e da escola, destaca Pretto (2004). E essa lógica vertical e massificadora que trata conteúdos como produtos distribuídos em larga escala, presencial, a distância ou online, ainda parece estar presente no currículo, diz o autor.

Aliás, há muito tempo Pretto (2004, p. 10) vem denunciando a ausência do campo da cultura nas propostas curriculares e para ele, na dinâmica das relações "é a cultura que dá vida à nossa vida”. Ou seja, é da interação e convivência entre as culturas com suas ambiguidades e potencialidades que emergem dessa coexistência, que podemos enriquecer os processos educativos baseados na horizontalidade.

Assim, refazendo a pergunta sobre a relação entre mídia e currículo, incluímos a cultura digital e seus cruzamentos de saberes e práticas em que o "doméstico" e o "popular" aparecem como gêneros estéticos e políticas ambivalentes. Nesse processo, também temos as rupturas e os encurtamentos de distâncias promovidos pelas tecnologias digitais por um lado e a projeção de conteúdos íntimos como promessas de acessibilidade, imediatez e horizontalidade por outro, que nos remetem à ideia da política sem mediações nem representações (LATOUR, 2012). E esse movimento de celebridades emergentes com os reality-shows e nova "entronização do eu" não está alheio a alguns movimentos do currículo e da pedagogia, que colocam no centro a "expressividade do eu" e a converte na medida do todo, como diz Sibilia (2008), inundando as salas de aula de afetos confessionais, por exemplo, através de portfólios cada vez mais personalizados ou através de escritas ou produções audiovisuais sobre a subjetividade, lembra Dussel (2013). Sem falar nos memes, vídeos virais e outros que parecem se tornar o novo currículo da cultura de massas, agora em redes.

Podemos perguntar qual o lugar destas práticas midiáticas no currículo, pois sabemos que "os meios digitais instalam certas formas culturais e operações com a cultura e os saberes que não são neutros, mas que dão forma a participação e, por vezes, certas vozes que se expressam marginalizam outras formas de conteúdos de expressão. Assim, pensar as tecnologias no currículo implica pensar também seus usos e presenças em pelo menos dois sentidos: na perspectiva pedagógica escolar e acadêmica e na perspectiva de um uso mais amplo de aprendizagens mediadas pela escola e pela cultura em geral. Ocorre que nem sempre tais perspectivas coincidem, pois o que entendemos que se deve ensinar na escola está mudando 
muito com as novas práticas culturais propiciadas pelas tecnologias digitais. Ou seja, hoje lidamos com conhecimentos e práticas culturais que até pouco tempo não existiam e nem valorávamos, e que agora redefinem a demanda da escola ou o que ela tem que ensinar. Por isso, há que distinguir a presença da tecnologia na escola de um uso "estritamente pedagógico" associado ao currículo que poderia excluir saberes e conhecimentos novos que não estão contemplados mas que seriam muito importantes para que os alunos aprendessem. Embora seja difícil abordar questões por vezes tão amplas, temos que nos perguntar se isso caberia à escola ou se eles aprendem fora dela e/ou com outras mediações.

$\mathrm{Na}$ tentativa de reorganizar um currículo herdado da modernidade nestas novas condições, alguns estudos têm radicalizado em certas orientações para recolocar o currículo diante dos desafios contemporâneos. A teoria do ator em rede, as práticas disruptivas, e as leituras transversais que pensam o tempo-espaço dos objetos imaginando conexões entre os elementos "diferentes" podem ser pistas ou indícios para produção de novos sentidos, diz Dussel (2013).

Com inspiração na reflexão da autora, muitas são as perguntas que podemos fazer: quais propostas curriculares podem evidenciar as grandes corporações que organizam o mundo, suas formas culturais privilegiadas, seus modelos de negócio, suas linguagens e suas estéticas, bem como sobre as oportunidades de a escola promover um trabalho sobre estar nas redes como reflexão crítica diante do mundo em que vivemos? Que forma terá um currículo que incorpore, não só os meios digitais e suas tendências na direção de um "regime de opinião", da imediatez, da emocionalidade, e da cultura conforme "a medida do indivíduo". Mas também a partir de outras questões que hoje interpelam a educação, para além dos usos dos celulares e smartphones em sala de aula, como por exemplo, as Fake News, controle de dados, liberdade e vigilância nas redes, desenvolvimento da inteligência artificial com a redefinição do que divide orgânico e artificial, robótica educativa e social, realidade aumentada, imagens sem referente (RIVOLTELLA \& ROSSI, 2019).

Complexos diálogos entre a história e a política levam Dussel a questionar como seria um "anti-currículo": "Pode um currículo representar a heterogeneidade, a descontinuidade, a multiplicidade e ainda assim ser legível e orientar as práticas? E ao torná-lo múltiplo, rizomático e plural, confrontaria os problemas e desafios da contemporaneidade?” (2013, p. 30). Essas são perguntas que não encontram respostas fáceis; mas, para a autora, o fato de formulá-las já 
sinaliza uma relação diferente com a cultura digital que hoje está presente em grande parte das escolas.

Nessa perspectiva, a teoria do currículo poderia sinalizar outras formas de texto e organização curricular com inspirações em experiências artísticas e outras estéticas que produzissem práticas de leitura, produção e socialização mais complexas e menos automatizadas, sem renunciar da inteligibilidade. Formas curriculares simplexas (BERTHOZ, 2009) que contemplassem a abertura ao comum e aos elementos da tradição do currículo moderno que são válidos e que não seria desejável desconsiderar. Uma teoria curricular que não abandone a busca por novos mapas que transitam saberes e permitem localizar-se em outros territórios e nem renunciem a "anti-monumentos" que sugerem inclusões e exclusões do anticanon da fluidez, diz Dussel, para quem "no momento pós-critico, não se trata de suspender o gesto radical; e sim de discutir onde e com quem os próximos passos serão dados" (2013, p. 32).

Nesse contexto, tão importantes quanto novas inspirações é recuperar certos processos e práticas de imersão cultural como oportunidades de entender o acesso à informação e aos espaços da cultura propiciados pelo acesso ao saber em suas diversas formas e mobilidades para além da sala de aula: viagens, visitas, cinemas, bibliotecas, jornais, revistas etc. Parece óbvio reafirmar que tal aspecto faz parte da formação, mas como diz Pretto (2004), a maioria das reformas curriculares ainda demonstra uma compreensão equivocada deste processo, pois parte do pressuposto que os conhecimentos continuam "arrumados em caixinhas" e que os eixos transversais por si só integrariam tais conhecimentos e saberes, que por sua vez, ainda continuam separados em seus próprios domínios, apesar de uma linha que os integrariam. Para o autor, essa linha tênue "não suporta todo o peso dessa estrutura vencida, totalmente montada a partir da ideia das próprias caixinhas: dos conteúdos e dos saberes partidos. E a vida, como sempre, segue do lado de fora, sendo trazida, no máximo, para exemplificar esses processos" (PRETTO, 2004, p. 13).

E para trazer outras dimensões da vida nesse espaço, Pretto (2017) analisa a perspectiva de uma ciência aberta e colaborativa a partir das possibilidades da filosofia hacker (HIMANEN, 2001) como o "desafio espiritual de nossa época” e destaca que: “

Outra cultura se estabelece ao enfatizarmos a paixão, o trabalho solidário e colaborativo como elementos socialmente necessários para a construção de um mundo sustentável. Entretenimento, trabalho, cultura, educação, ciência, tecnologias, todos os campos podem e deveriam estar imersos nessa cultura, 
onde o prazer em construir seja o mote realizador das ações (PRETTO, 2017, p. 39).

O desafio de pensar outras metáforas, das caixas às obras abertas, tal como Pretto sugere mencionando os parangolés de Oiticica, envolveria o sentido de uma participação que só existe enquanto incorporada e integrada à ideia de multiplicidade. Ao instaurar articulações diversas com as novas redes de conexões que revelem o comum, a diferença, a singularidade, a pluralidade e a intensidade das experiências e saberes, novos elementos podem ser incorporados a todos esses processos, educacionais, artísticos e culturais, redimensionando as negociações que acontecem de forma permanente. Assim, "a mídia passa a desempenhar um fundamental papel interagindo diretamente com o cotidiano escolar e, principalmente, com a forma de se conceber o currículo." (PRETTO, 2004, p. 25).

Desse modo, podemos chegar à ideia/metáfora do currículo como rede ou rizoma. Com a internet e os novos meios digitais, as mudanças tecnoculturais que promovem outras formas de produção, compartilhamento e outras hierarquia de saberes instalam novas práticas de cidadania instrumental e de pertencimento em múltiplas linguagens e suportes, e reorganizam a ideia de cultura comum que estruturava o currículo escolar e o próprio lugar dos saberes articulados em redes. E tais articulações fazem parte desse ecossistema comunicativo, pedagógico e cultural que é a escola com seus diálogos e negociações entre mídia, cultura digital, cotidiano escolar, conhecimento e currículo.

Aliada à metáfora, o currículo pode ser entendido como um texto que se faz, refaz e desfaz na prática pedagógica e nas múltiplas interações entre professores e alunos em sala de aula e fora dela. Texto plural e aberto construído coletivamente, que desloca saberes e que reconfigura relações, momentos e tempos das aprendizagens. Assim, as autorias de professores e alunos não deixam de existir, pois a mudança de lugar de tais papéis e a impermanência de certos conteúdos que podem se tornar outros, não acarretam necessariamente “[...] a perda da capacidade humana de construir, preservar e cuidar de um mundo que nos pode sobreviver e permanecer um lugar adequado à vida para os que vêm depois”, diz Arendt (1997).

Nesse contexto, seria possível reorganizar um projeto curricular considerando o entorno tecnológico nessas novas condições, com práticas disruptivas e transversais que pudessem traduzir e colocar em questão a rigidez de certos conteúdos a partir do movimento e fluidez das ideias no tempo-espaço expressando outras formas de texto curricular, com inspirações na filosofia, arte, ciência e em outras experiências estéticas. Parece que a ideia de "currículo breve" 
proposta pela metodologia dos Episódios de Aprendizagem Situada (EAS) (RIVOLTELLA, 2103), caminha nesta direção. Trata-se de uma direção que se coloca em continuidade com a ideia do curriculo de Freinet: um currículo individual, com plano de trabalho do estudante, aberto ao que a contemporaneidade vem propondo, sempre novamente redefinido, coconstruído colaborativamente entre os estudantes, incluindo práticas de escrita coletiva, momentos de trocas culturais, e intercâmbios com a comunidade na qual a escola esta inserida.

\section{EAS E O CURRÍCULO BREVE}

No espaço-tempo da escola, as estratégias para integrar significativamente os usos das tecnologias e seus dispositivos no currículo têm solicitado um trabalho com questões e competências específicas que interpelam à didática diferentes abordagens de ensino sobre novas modalidades do processo de ensinar e aprender. Entre esses modelos, destacamos o conceito de Episódios de Aprendizagem Situada (EAS).

O conceito refere-se a uma metodologia didática, que tem origem em três ideias: 1) a oportunidade, para uma didática coerente com os tempos de atenção de crianças e jovens de hoje, de organizar as atividades na sala de aula conforme as indicações do microlearning, ou seja, uma teoria da aprendizagem que sugere o uso de micro-conteúdos e de micro-atividades de modo que a carga cognitiva proposta seja coerente com as possibilidades de aprender dos estudantes; 2) a importância que a aprendizagem seja sempre situada. Isso quer dizer duas coisas. A primeira é que qualquer aprendizagem humana, embora abstrata e conceitual, sempre tem que ver com o papel do corpo, conforme a perspectiva da Embodied Cognition (RIVOLTELLA; ROSSI, 2019). A segunda é que na didática, o ensino é tanto mais significativo e eficaz quanto mais se refere às experiências e práticas contextualizadas; 3) a ideia cognitivista de aprendizagem signficativa (AUSUBEL, 1963), que é o contrário da aprendizagem mecânica, diz respeito à apropriação crítica de significados.

A metodologia EAS também se configura como uma proposta de integração dos dispositivos móveis na didática, diz respeito a "um processo de aprendizagem informal relacionado aos fenômenos que atravessam as culturas de mídias atuais, suas fragmentações e recombinações de formatos textuais e transmídiáticos" (RIVOLTELLA, 2013, p. 51-52) e fundamenta-se em 4 ideias-chave: o ensino como design, o aprender fazendo, oflipped teaching e a neurodidática, que podem ser assim resumidas (RIVOLTELLA, 2015): 
1. Ensino como design: envolve as dimensões do planejamento organizativo, da estética da forma ou estilo, e dos conteúdos da cultura. Entende o professor como um arquiteto da formação (LAURILLARD, 2012); o ensino como um trabalho com as multiliteracies no contexto da vida sociocultural dos estudantes (COPE \& KALANTZIS, 2000); e a didática como montagem de objetos culturais a partir da dialética entre montagem e desmontagem (FRANCASTEL citado em RIVOLTELLA, 2015);

2. Aprender fazendo: envolve duas perspectivas: 1) o trabalho com laboratório como dispositivo e método didático com seus mediadores analógicos e ativos (DAMIANO, 2013) para além do espaço ou sala de aula, conforme os princípios da escola ativa; 2) o entendimento dos pensamentos como hábitos de ação, conforme a epistemologia genética de Piaget (RIVOLTELLA, 2015), ou seja, entendimento de que a função do pensamento é produzir ações;

3. Flipped teaching: a inversão da lógica da didática tradicional de ensino (aula expositiva com tarefas para o aluno fazer em casa) de modo a primeiro solicitar ao aluno uma busca de informações sobre o tema da aula em casa para depois discutir em sala de aula e compartilhar seus entendimentos e suas dúvidas por meio de atividades que envolvam a aplicação de tais conteúdos. A ideia da flippped lesson, introduzida por Mazur (2007) na metodologia do eLearning há trinta anos, na verdade já havia sido trabalhada e/ou antecipada na ideia de Freinet e sua lição a posteriori (FREINET \& SALENGROS, 1960), ou seja, a hipótese de que a fala do professor é muito mais eficaz se previamente os estudantes já tenham trabalhado os conteúdos e problemas que depois ele iria destacar. Hoje esta prática de ensino é difundida em diversos países por diferentes autores;

4. Interseção entre neurociências e didática: envolve 3 entendimentos: 1) o paradigma da simplexidade (BERTHOZ, 2009) sobre como os organismos vivos enfrentam a complexidade e desenvolvem dispositivos intermediários que em vez de simplificar as coisas podem reduzir a complexidade desenvolvendo uma função de mediação na seleção e busca de informações, tornando o EAS um dispositivo simplexo; 2) o sistema corpo-mente-cérebro que fundamenta a base da aprendizagem redimensionando suas modalidades fundamentais; 3 ) circuito espelho e a ressignificação do papel da repetição, da imitação e da experiência nos processos de aprendizagem.

A metodologia EAS organiza-se a partir de uma estrutura que prevê três momentos em cada aula: 1) momento prévio: uma situação-estímulo que encaminha uma atividade preparatória individual aos alunos e que termina em sala de aula, com um quadro conceitual 
feito pelo professor; 2) momento operativo: depois do quadro conceitual, o professor propõe uma microatividade de produção em grupo, em que o aluno deve resolver um problema ou produzir algum conteúdo sobre a situação-estímulo. Este momento vai ser concluído com uma apresentação e discussão dos trabalhos dos grupos; 3) momento re-estruturador: um debriefing sobre o que aconteceu nos momentos anteriores, com retorno sobre os processos ativados e conceitos que emergiram de modo a refletir aspectos a serem salientados e/ou corrigir erros, equívocos e falsas crenças que se produziram naquele processo (RIVOLTELLA, 2013).

Diante de tal proposta, o currículo na escola desenvolve uma função cultural para

favorecer a ordem ao caos entre os alunos, diz Rivoltella inspirado na filosofia de Deleuze e Guattari (1991).

A filosofia, como a ciência e a arte, desenha um plano, fixa conceitos e povoa o plano de personagens (DELEUZE; GUATTARI, 1991). Rivoltella esclarece que isso também se faz com a didática na organização do currículo:

Plano: é o contexto, o plano de fundo, um framework, que diz respeito à cultura, ao entorno. Desenha-se um plano no currículo para construir um fundo integrador, identificar macro construto/ pensamento da realidade disciplinar para trabalhar. O plano é a moldura da didática, é o espaço no qual os conceitos se situam e têm sentido.

Conceitos: são os nós epistemológicos de um campo de experiência que fundam uma disciplina, e que são geradores e consistentes para recuperar tematicamente o que de mais importante existe. Na atividade didática os conceitos são os conteúdos sobre os quais o professor trabalha com os alunos; esses conteúdos se articulam com o plano didático, na relação dialética entre o fundo e o primeiro plano.

Personagem: aquilo que deriva do conceito, o que permite 'criar" e dar corpo ao conceito, o que articula os tratos existenciais em que o pensamento pode ser desdobrado. Sempre o professor se serve de uma narrativa para mediar os conceitos: personagem é parte desta narrativa, favorece a introdução de exemplos, e materializa as ideias contextualizando o pensamento.

Tais aspectos podem ser articulados com a metodologia dos Episódios de Aprendizagem Situada (EAS), que permite olhar o plano/situar o entorno, fixar conceitos na disciplina e no campo da experiência, e produzir/transpor personagens a isso tudo. Nesses três momentos podese individualizar o espaço de organização do currículo breve, ou seja, de uma necessária 
rearticulação dos conteúdos com os quais se trabalha na escola entre professores e alunos. A escola precisa desta rearticulação por duas principais razões:

1. Diante do tema obsessivo de que "precisamos mais tempo para desenvolver atividades em sala", qualquer didática ativa ganha em significado e profundidade. Ao lado do "mas se perde tempo" temos o argumento de que "ao mesmo tempo faz menos", e assim parece ser inevitável que o currículo reduza quantitativamente os temas, construtos e o saber. Para produzir aprendizagens significativas - come sugerem Ausubel (1963) e Bruner (2000) - tem que reduzir o número dos conteúdos trabalhados.

2. Além disso, tem que considerar o dinamismo do saber na sociedade contemporânea. É um dinamismo rápido, que muda assuntos e ideias com grande velocidade e que produz uma enorme quantidade de informações. Por exemplo, nos anos 1990, autores como Jorge Amado eram contemporâneos e hoje Jorge Amado é um dos mais importantes escritores do século passado, e isso quer dizer que tempo passa e os conteúdos que a escola deveria trabalhar aumentam. Isso vale para qualquer disciplina.

Assim, se o saber está sempre aumentando, há que escolher quais conteúdos trabalhar. Gardner (1991) sugere dois critérios de escolha: ser exemplar (ao abordar um tema, se aborda os outros); ser transferível (ao trabalhar forma-conteúdo, esta se aplica a outros âmbitos e experiências). O conteúdo exemplar é representativo de um vasto conjunto de conteúdos reconduzíveis a eles, e a transferência não é só de conteúdos mas, sobretudo, de posturas, capacidades, habilidades e competências (por exemplo: a transferência de saber treina o pensamento lógico (filosófico), desenvolve a capacidade intelectual (neurociência), e desenvolve competências (lógica didática).

A metodologia EAS se situa nesta mesma lógica. Quando o professor trabalha com EAS na sala de aula, a perspectiva é a da educação lenta (FRANCESCH, 2009): precisa assegurar o tempo aos estudantes para colocarem-se diante dos problemas, tentar soluções próprias, dar tempo para os grupos trabalharem e discutirem, e propiciar o tempo ao momento metacognitivo do debriefing. A rapidez, a corrida porque temos muitas coisas a fazer é inimiga da produção de conhecimentos e do desenvolvimento de competências. Uma das consequências será certa diminuição de conteúdos trabalhados: mas trabalhar em profundidade e assim fazer com que toda a turma possa desenvolver aprendizagem significativa tem um preço, ou seja, "fazer menos". Aqui a metodologia EAS quebra ou rompe o dispositivo de escola: a escola se 
transforma em "escola do aluno", espaço para construir sentidos, lugar democrático no qual todos devem ter a mesma possibilidade de realização das próprias possibilidades.

\section{ALGUMAS NARRATIVAS SOBRE EAS NA FORMAÇÃO DE PROFESSORAS E PROFESSORES}

No contexto de uma pesquisa que previa uma aproximação à metodologia EAS em diferentes níveis de ensino, a escolha de tal metodologia no contexto de uma disciplina de um Curso de Pós-Graduação em Educação, fundamenta-se em algumas possibilidades: lidar com as continuidades e rupturas nas experiências cotidianas dentro e fora da escola e a necessidade de considerar outros contextos de aprendizagem na formação cultural; trabalhar com as competências nos âmbitos das práticas de leitura, escrita, criação e resolução de problemas, olhar de si e do outro; tensionar o papel da imagem, da corporeidade, do fazer-refletir, da motivação de professores e estudantes em seu processo formativo; ressignificar o uso dos dispositivos móveis na produção audiovisual e midiática, suas linguagens e interações em redes.

A metodologia possibilita também tensionar o tempo breve, os diferentes ritmos de cada um e as negociações no trabalho de grupo, o necessário tempo da reflexão e da significação, das reproduções interpretativas, bem como o tempo de aprendizagem de cada um, nem sempre sintonizado com os tempos e demandas da instituição. Assim, a aproximação com tal metodologia poderia construir pistas para resistir à pouca atenção dada a certos processos didáticos e ao utilitarismo do saber na formação de professores de modo a construir outra relação com o tempo da aprendizagem em uma sociedade cada vez mais acelerada, para prestar mais atenção aos detalhes e às intencionalidades dos diferentes gestos nas relações pedagógicas (RIVOLTELLA, 2013; 2020).

As práticas disruptivas com EAS potencializam a noção de agência de estudantes e a construção de saberes ao lado da reflexão sobre conteúdos tratados, sobre mídias e dispositivos em sala de aula, e sobre as mediações no ecossistema comunicativo, pedagógico e cultural que é a escola- (FANTIN, 2018). E como em geral as aulas na formação universitária ocorrem por meio de discussão de texto e seminários, esta proposta buscou experimentar uma didática multimodal, inspirada em pesquisas de intervenção didática desenvolvidas em escolas de ensino fundamental de diversos contextos socioculturais (FANTIN, 2015, 2016).

Aliado a isso, as possibilidades de práticas inovadoras com o uso das tecnologias na perspectiva da mídia-educação podem oferecer aos estudantes da graduação, oportunidades 
valiosas para a construção de ambientes de aprendizagem aprimorados, interativos, colaborativos, envolventes e mais inclusivos. Para Sankey, Birch e Gardiner (2010), principal motivação que a didática multimodal propicia ao incorporar tecnologias educativas no currículo é o desejo de melhorar o envolvimento e a aprendizagem dos alunos. Afinal, entre tantas questões elencadas na primeira sessão do texto, o uso de multimídia no ensino oferece oportunidades para apresentar as múltiplas representações de conteúdo (texto, vídeo, áudio, imagens, elementos interativos) e contemplar de forma significativa os diferentes estilos de aprendizagem de estudantes, sem esquecer da dimensão do prazer na realização das ações.

A seguir, apresentamos uma breve síntese das propostas desenvolvidas e alguns desdobramentos da metodologia EAS a fim de situar e dar visibilidade a alguns processos de reflexão desencadeados entre os estudantes.

No momento inicial dos encontros, sempre buscávamos partir do que o grupo já sabia para então levantar questões e problematizá-las de modo a alicerçar a discussão, que nem sempre se limitava ao texto indicado para leitura prévia. Algumas estratégias para este momento envolviam braimstorming, vídeo-estímulo sobre o tema, textos, imagens, músicas, performances, fragmentos de entrevista relacionada ao assunto, breve exposição situando o conteúdo a partir de outros autores e abordagens.

No momento seguinte, operativo, as atividades em grupos ou em pares eram propostas com o objetivo de aprofundar as questões discutidas/desencadeadas/sugeridas visando aprofundar a discussão e/ou operar certos conceitos tratados nos textos a partir da experiência de cada um, agora compartilhada no grupo. E isso envolvia atividades como: estudos de caso em que evidenciassem situações relacionadas ao assunto; resolução de situações-problemas a partir de questões dadas; produção de materiais ou textos multimodais, escritos e/ou audiovisuais utilizando diversas linguagens, suportes e artefatos sobre um tema proposto/discutido. Em seguida, era feita a socialização das questões discutidas e/ou das produções realizadas no grande grupo.

No momento final, re-estruturador, o debriefing acontecia para evidenciar o que havíamos feito/aprendido a partir do envolvimento de cada um na dinâmica proposta, a fim de retomar os conceitos operados nas atividades e tensionar as dúvidas e os questionamentos que surgiram nas discussões. Era o momento de retomar e avaliar o processo desencadeado, as aprendizagens e apropriações, os saberes e não saberes, as formas de participação e os novos encaminhamentos. Além de rodadas de conversa, nessa reflexão sobre o percurso de 
aprendizagem construído na aula por vezes utilizamos outras estratégias de avaliação como, por exemplo, o uso de metáforas.

Ao refletir sobre a didática multimodal aplicada em um contexto formativo a partir da metodologia dos Episódios de Aprendizagem Situada, EAS, trazemos algumas vozes de estudantes a respeito dessas experiências de modo a evidenciar narrativas que se aproximam de uma prática disruptiva no processo de ensinar-aprender-comunicar. As falas a seguir foram compartilhadas no final de cada encontro, e podem dar uma ideia mais aproximada de como esses processos foram significativos para o grupo:

- "Gostei da dinâmica, a aula foi hipertextual, abordou conceitos de forma dinâmica e compreensivel com abertura a outras perspectivas" (AB);

- "Na aula de hoje houve produção e diferentes formas de apropriação (vídeo, reflexão dos textos, dinâmicas para trocas e para produzir, vivenciar. O foco na experiência e no estudo de caso vislumbrou coisas que eu nunca tinha pensado" $(W)$;

- "Gostei da metodologia, trabalhou o individual e o coletivo, fez um bom fechamento" $(G)$;

- "Dinâmica interessante mas fico um pouco preocupada com o aprofundamento das questões do texto que sentia necessidade de discutir mais" (AP);

- "Trouxe o conceito de mídia-educação dentro da aula, aplicou na prática e vivenciamos isso" $(\mathrm{J})$;

- "Eu leio, anoto, reflito ativamente mas sou só eu, e na aula se expande para "um eu maior", dinâmico com ações que contribuem" $(F)$;

- "Esclarecimento. Trouxe reflexões e dúvidas e aqui você conseguiu esclarecer, parece simples mas é complexo, e você passou para a gente de forma a conseguir compreender" (JD).

Os fragmentos acima revelam aspectos das atividades avaliadas no final de cada encontro, e como é possível perceber, em alguns depoimentos, a perspectiva de uma didática multimodal com EAS. Foi uma importante ocasião para identificar como certas tecnologias se correlacionam não só com a sociedade contemporânea, mas com processos cognitivos específicos. Tal proposta didática-metodológica também permite maior flexibilidade na interação professor-aluno e pode melhorar o ambiente de aprendizagem, como destacam Marchetti e Cullen (2016).

As narrativas a seguir demonstram uma perspectiva mais ampla, realizada no final do curso por ocasião da avaliação da disciplina a fim de enfatizar a aprendizagens dos conteúdos, a participação nas dinâmicas propostas e a própria didática multimodal nos EAS. A avaliação foi feita por metáforas, desenhadas e escritas em papel, tipo um post it, para depois compartilhar o sentido com o grupo: 
- 'Lâmpada. Como se ao aprender com o outro e de diferentes formas, acendesse uma luz. O compartilhamento das ideias, conceitos, visões contribui para a formação de novas ideias sobre o objeto estudado" (JM);

- "Quebra-cabeça(...). Práticas reflexivas com sentido dentro de cada texto associando com as ideias debatidas. Oportunidades de trocar experiências entre nós mas que eram complementadas com sínteses com consistência, mostrando que não existe um método fechado mas que se pode construir através da prática para podermos entender o sentido disso que fazemos $e$ aprendemos." (T);

- "Mapa conceitual. A disciplina permitiu ampliar o conhecimento desconstruindo e reconstruindo conceitos; ampliou minhas habilidades cognitivas, minha escrita; aguçou minha curiosidade sobre novos temas, autores e conceitos. Permitiu socializar e discutir conhecimentos $e$ experiências a partir de diferentes linguagens; desenvolveu parcerias inclusive fazer novas amizades" $(V)$;

- "Espiral. A disciplina foi um espiral de aprendizagem em movimento de conhecer, questionar e reaprender com avanços e retornos constantes em outros pontos. A importância do embasamento teórico que eu não tinha. Os momentos de explanação foram muito importantes e fundamentais para repensar conceitos que eu não tinha claro, além das atividades em grupo e debates" $(S)$.

Ainda que certas narrativas explicitem mais o sentido da experiência de aprendizagem com EAS, algumas avaliações e metáforas traduzem também o sentido de outras possibilidades que sinalizamos para o currículo ao longo desta reflexão: a questão do "pouco tempo", da escolha de "certos conteúdos" para trabalhar em profundidade, do espaço de liberdade de trazer e/ou incluir outras questões que não estavam previamente delineadas, da incompletude de certos processos e das necessárias mediações:

- "Meia lua-cheia. A lua em seu processo de tornar-se cheia com a sensação de que 2 créditos é pouco, mas 4 também seria. Uma formação profunda e pertinente que visualiza tanta coisa. Impressão de que percorremos um caminho, ou metade dele, e ficou esse horizonte a ser preenchido. Não que isso seja ruim, mas queria continuar para andar um pouco mais juntos. Todavia fica o horizonte à nossa frente para continuarmos caminhando" $(J D)$;

- "Menina com um notebook". Ficou a reflexão diferente de uma formação com cenários mais ativos. A disciplina foi muito significativa, muitas perguntas ficaram mas outras foram incluídas e assim ampliou a possibilidade de procurar as respostas" $(F)$;

- "Experiência do pote de feijão". A disciplina passou rápido demais mas plena de luz, dinâmica, porém foi um ciclo produtivo de criação, participação e florescimento - assim como plantar feijão no algodão. Às vezes as explanações foram apressadas e ficaram muitas questões em aberto, mas foram ótimas. O contato com autores, a ajuda dos colegas, tudo cresceu rápido, e isso dá satisfação e infere na aprendizagem "(E); 
- “Simbiose”. Trouxe novas inquietações e mutação. Simbiose entre dois seres em conhecimento, e os estudos de caso trouxeram mais perguntas que respostas, o que leva a novas buscas" (AP).

Embora o uso de metáforas possa ser aprofundado, neste momento consideramos que revelam aspectos do aprender-ensinar-comunicar a partir de outros modos de construir conhecimento ressignificando o sentido de ler, ver, fazer, aprender, refletir e compartilhar. Pistas para um exercício de pensar um currículo outro, que vai sendo construído na tessitura de uma educação entendida também como "ação cultural para a liberdade", como diria Paulo Freire (1979), e que justamente por isso não está isenta de contradição e pode ser compreendida na dialética entre subjetividade e objetividade. Para Freire, estamos inseridos no tempo, e não imersos nele e movemo-nos no mundo em que fazemos escolhas, optamos, decidimos, valoramos e nos orientamos. Nesse processo, o ato de estudar "é uma atitude em frente ao mundo", e envolve "assumir uma postura curiosa. A de quem pergunta, a de quem indaga, a de quem busca” (1979, p. 11). Assim, em sua visão, "não se mede o estudo pelo número de páginas lidas numa noite ou pela quantidade de livros lidos num semestre. Estudar não é um ato de consumir ideias, mas de criá-las e recriá-las" (FREIRE, 1979, p. 12).

E é nessa perspectiva (re)criadora, de autoria compartilhada na construção da aula, e consequentemente de outra ideia de currículo, que vislumbramos a possibilidade "flexibilizar o dispositivo de poder" da escola e sua rigidez curricular sem abrir mão do "núcleo válido". Esboços e traços de um desenho construído por muitas mãos que deixaram marcas e sinalizaram experiências de conhecimento elaborados em parceria, entre o que era proposto pela professora, inicialmente contemplado na disciplina curricular, e o que era acolhido pelo grupo na busca de significação dos saberes por meio de fazeres outros. E para nós, isso se aproxima de práticas libertadoras e disruptivas.

A intensa participação nas aulas e o constante diálogo do grupo com os territórios da escola e de outros espaços educativos e culturais, trazidos na multiplicidade das experiências e dos textos por todos que construíram esses encontros, possibilitaram outros olhares para suas práticas e para a pesquisa, e isso pode sinalizar pistas de uma prática transformada e em transformação.

\section{CONCLUSÃO}


A experiência na sala de aula demonstra a possibilidade de uma abordagem diferente do currículo. O conceito, como também a parte teórica do artigo, pode ser entendido desarticulando o discurso pedagógico tradicional, de modo que o currículo possa deixar de ser considerado uma moldura rígida que dá visibilidade ao dispositivo da escola - no sentido foucaultiano -, e possa ser reconceitualizado como um texto que se faz e desfaz na prática pedagógica e nas interações entre professores e alunos em sala de aula. Assim, o que se experimenta é um deslocamento do plano institucional (programas, estruturas) ao plano biográfico individual e/ou coletivo: como a pedagogia ativa destacou, nesta perspectiva o currículo se torna a trajetória (do latim "cursus, currere") que o estudante vem descrevendo e construindo acompanhado pelo professor em uma troca constante de ideias e práticas. Currículo como um texto aberto e plural que se faz e refaz a partir da descrição da história de aprendizagem de cada um em contato com outras histórias, assegurando mais espaços para a invenção e criação, para além dos espaços de poder. Enfim, um currículo que possa ser entendido também como uma prática de liberdade e de transformação.

Nessa perspectiva, a metodologia dos Episódios de Aprendizagem Situada, EAS, é uma ferramenta pedagógica e didática para materializar este deslocamento, pelo menos em dois sentidos. Em primeiro lugar, porque favorece o trabalho de investigação dos alunos, a colaboração no grupo, a reflexividade crítica sobre os processos. Em segundo lugar, porque viabiliza práticas multimodais em tempos breves, respeitando o ritmo de aprendizagem dos alunos.

Por fim, pensar as culturas na escola em diálogo com tal perspectiva metodológica, repercute em outras possibilidades de entender o currículo. Isso nos leva não apenas a questionar certos modelos mas a reafirmar a importância de construir experiências formativas com múltiplos sentidos e com uma perspectiva criadora e transformadora, que possa envolver o sonho, o silêncio, a polifonia as vozes, as imagens e a beleza que a prática educativa pode ter.

\section{REFERÊNCIAS}

ALVES, Nilda. Formação de docentes e currículos para além da resistência. Revista Brasileira de Educação, v.22, n. 71, 2017.

ARENDT, Hannah. Entre passado e futuro. 4. ed. São Paulo: Perspectiva, 1997.

AUSUBEL, David P. The Psychology of Meaningful Verbal Learning. New York: Grune \& Stratton, 1963. 
BASAGLIA, Franco. A psiquiatria alternativa. Contra o pessimismo da razão, o otimismo da prática. São Paulo: Brasil Debates, 1979.

BERTHOZ, Alain. La Simplexité. Paris: Odile Jakob, 2009.

BRUNER, Jerome. La cultura dell'educazione. Milano:Feltrinelli, 2000.

COPE, Bill \& KALANTZIS, Mary (Eds.). Multiliteracies. London, Routledge. 2000.

DAMIANO, Elio. Didattica come teoria della mediazione. Milano:Franco Angeli, 2013.

DELEUZE, Gilles; GUATTARI, Félix. Qu'est-ce que la philosophie? Paris: Les Éditions de Minuit, 1991.

DUSSEL, Ines. Curriculum y autoridad cultural. In: MORGADO, José C.; SANTOS, Lucíola Licínio C. P.; PARAISO, Marlucy A. (Orgs). Estudos Curriculares: um debate contemporâneo. Curitiba: CRV, 2013. p. 10-36.

DUSSEL, Ines. ¿Es el curriculum escolar relevante en la cultura digital? Debates y desafíos sobre la autoridad cultural contemporánea. Archivos Analíticos de Políticas Educativas. V. 22, N. 24, Abril 2014. Disponível em: http://epaa.asu.edu/ojs/. Acesso em: 20 abr. 2020.

FANTIN, Monica. Mídia-educação no ensino e o currículo como prática cultural. Currículo sem Fronteiras, v. 12, p.437-452, 2012. Disponível em:

http://www.curriculosemfronteiras.org/vol12iss2articles/fantin.pdf. Acesso em: 22 abr. 2020.

FANTIN, Monica. Novos Paradigmas da Didática e a Proposta Metodológica dos Episódios de Aprendizagem Situada, EAS. Educação \&Realidade. v. 40, n. 2, p.443 -464, 2015. Disponível em: http://www.scielo.br/scielo.php?script=sci arttext\&pid=S217562362015000200443\&lng=pt\&nrm=iso\&tlng=pt. Acesso em: 18 abr. 2020.

FANTIN, Monica. Approssimazioni: EAS, Media Education e partecipazione nel território. In: LIMONE, P.; PARMIGIANI, D. (a cura di). Modelli pedagogici e pratiche didattiche per la formazione iniziale e in servizio degli insegnanti. Bari: Progedit, 2017, pp. 385-395.

FANTIN, Monica. Currículo e entornos tecnológicos, didáticos e culturais. V Web

Curriculo: Educação e Cultural digital. São Paulo: PUC, 16 a 18 de Outubro 2017.

FANTIN, Monica. Didattica multimodale nella scuola e nella formazione degli inseganti.

Prentazione In Convegno SIREM 2018: Linguaggi e animazione digitale. Scuola. Territorio. Università. Bologna, 5-6 aprile 2018.

FIDLER, Roger. Mediamorphosis. Understanding New Media. New York: Pine Forge Press 1997.

FLORIDI, Luciano. The Fourth Revolution. How the infosphere is reshaping human reality. Oxford. Oxford University Press 2014. 
FRANCESCH, Joan D. Elogio de l'educacion lenta. Barcelona: Editorial Grào, 2009.

FREINET, Celestin, SALENGROS, Roger. Moderniser l'école. Paris: Bibliothèque de l'école moderne 1960.

FREIRE, Paulo. Ação cultural para a liberdade: e outros escritos. 4. ed. Rio de Janeiro: Paz \& Terra, 1979.

FREIRE, Paulo. Pedagogia da esperança: um reencontro com a pedagogia do oprimido. 23 ed. Rio de Janeiro: Paz \& Terra, 2016.

GARDNER, Howard. The unschooled mind: How children think and how schools should teach. New York: Basic Books 1991.

HIMANEN, Pekka. The Hacker Ethic. The Spirit of Information Age. London: Martin Secker \& Warburg 2001.

ITO, Misuko; BAUMER, Sonja; BITTANTI, Matteo; BOYD, Danah; CODY, Rachel; HERR-STEPHENSON, Becky et al. Hanging Out, Messing Around, and Geeking Out: Kids Living and Learning with New Media. Boston Mass: The MIT Press, 2010.

JENKINS, Henry. Cultura da convergência. 2. ed. São Paulo: Aleph, 2009.

LATOUR, Bruno. Reagregando o social: uma introdução à teoria do Ator-Rede. Salvador: EDUFBA, 2012.

LAURILLARD, Diana. Teaching as a Design Science: Building Pedagogical Patterns for Learning and Technology. London: Routledge, 2012.

MAZUR, Eric. Peer Instruction: getting students to think in class. New York: American Institute of Pyisics, 2007.

MOREIRA, Antonio F. B.; SILVA, Tomás T. Sociologia e teoria crítica do currículo: uma introdução. In: MOREIRA, Antonio F. B.; SILVA, Tomás T. (Orgs.). Curriculo, cultura e sociedade. São Paulo: Cortez, 1995. p. 7-37.

PRETTO, Nelson. Mídia, currículo e o negócio da educação. VI Colóquio sobre Questões curriculares. 2004. Disponível em:

https://blog.ufba.br/nlpretto/files/2009/11/pretto_cur_midia_1_1enviado.pdf. Acesso em: 30 set. 2017.

PRETTO, Nelson. Educações, Culturas e Hackers: escritos e reflexões. Salvador: EDUFBA, 2017.

RIVOLTELLA, Pier Cesare. Fare Didattica con gli EAS. Brescia: La Scuola, 2013.

RIVOLTELLA, Pier Cesare. Didattica inclusiva con gli EAS. Brescia: La Sucola, 2015. 
RIVOLTELLA, Pier Cesare. Che cos'è un EAS: L'idea, il metodo, la didatica. Brescia: La Scuola, 2016.

RIVOLTELLA, Pier Cesare. Un’idea di scuola. Morcelliana. Brescia, 2018.

RIVOLTELLA, Pier Cesare. Tempi di lettura. Media, pensiero, accelerazione. Brescie: Scholé 2020.

RIVOLTELLA, Pier Cesare; ROSSI, Pier Giuseppe. Il corpo e la macchina. Tecnologie, cultufra, educazione. Brescia: Scholé 2019.

SANKEY, Michael; BIRCH, Dawn. \& GARDINER, Michael. Engaging students through multimodal learning environments. Proceedings ascilite Sydney, 2010. Disponível em: http://ascilite.org.au/conferences/sydney10/procs/Sankey-full.pdf. Acesso em: 20 abr 2020.

SIBILIA, Paula. O show do eu: a intimidade como espetáculo. Rio de Janeiro: Nova Fronteira, 2008.

SIBILIA, Paula. Redes ou paredes: a escola em tempos de dispersão. Rio de Janeiro, Contraponto, 2012.

SILVA, Tomaz T. Identidades Terminais: as transformações na política da pedagogia e na pedagogia da política. Petrópolis: Vozes, 1996.

Recebido em: 01/05/2020

Aprovado em: 04/06/2020 